Available online on 15.02.2020 at http://jddtonline.info
Open Access to Pharmaceutical and Medical Research
unrestricted non-commercial use, provided the original work is properly cited

Open $\odot$ Access

Review Article

\title{
Role of Riyazat in prevention and control of lifestyle diseases: A review
}

\author{
Yasra Farooqui ${ }^{*}$, Mohd Yunus Siddiqui ${ }^{2}$, Amreen Zehra ${ }^{1}$, Maryam Zafar ${ }^{1}$ \\ 1-PG Scholar, Department of Moalejat, Ajmal Khan Tibbiya College, Faculty of Unani Medicine, Aligarh Muslim University, Aligarh \\ 2-Professor, Department of Moalejat, Ajmal Khan Tibbiya College, Faculty of Unani Medicine, Aligarh Muslim University, Aligarh
}

\begin{abstract}
Background: Riyazat (exercise) is a planned, structured and repetitive bodily movement that is done to improve or maintain physical fitness and overall health. It plays an important role not only in maintaining good health but also in preventing and curing certain ailments as well. Lifestyle diseases are ailments that are primarily based on the day to day habits of people. Lack of exercise and habits that detract people from the activity and push them towards a sedentary routine, these are the major causes which serve as an important factor in the rising prevalence of lifestyle diseases. Some of the emerging lifestyle diseases are obesity, hypertension, type 2 diabetes, cardiovascular dis eases, joint diseases and psychological disorders. Mortality and morbidity rates have also increased with increasing levels of these diseases. Frequent and consistent exercise helps in the prevention of these diseases. It helps in maintaining or losing weight, improves metabolic function and mental health by reducing stress. Many ancient Unani physicians like Hippocrates, Galen, Razi and Avicenna have discussed the beneficial effects of riyazat in their treatise. Conclusion: It is used as a regimental therapy that acts by inhibiting agglomeration of morbid material in the body and helps in revocation of waste products through natural routes, thus reducing risks for the development of various diseases. So there is an indispensable need to procure exercise regularly to forestall lifestyle diseases for the betterment of life.
\end{abstract}

Keywords: Riyazat, metabolic, ancient, regimental, morbid

Article Info: Received 21 Nov 2019; Review Completed 26 Jan 2020; Accepted 30 Jan 2020; Available online 15 Feb 2020

Cite this article as:

Farooqui Y, Siddiqui MY, Zehra A, Zafar M, Role of Riyazat in prevention and control of lifestyle diseases: A review, Journal of Drug Delivery and Therapeutics. 2020; 10(1-s):211-214 http://dx.doi.org/10.22270/jddt.v10i1-s.3929

*Address for Correspondence:

Yasra Farooqui, PG Scholar, Department of Moalejat, Ajmal Khan Tibbiya College, Faculty of Unani Medicine, Aligarh Muslim University, Aligarh

\section{Introduction:}

Exercise is a sequence of voluntary and continuous movements of the body which produces rapid and deep respiration ${ }^{1,2}$. Therapeutic exercise is the systematic and planned performance of movement of the body, specific postures, or physical activities intended to provide a patient to prevent impairments, enhance physical functions, and reduce health-related risk factors and to provide a feeling of well being. 3 The use of therapeutic exercise was recorded as early as 800 BC in the manuscript of Arth Veda. Many Unani physicians Hippocrates, Razi, Avicenna has well discussed regarding riyazat in his treatise. 4

In the Unani system of medicine, exercise is one of the sixteen methods of treatment of regimental therapy and is used as a voluntary movement with the purpose of tanqiya-emawad (evacuation of waste material), for purification of the body in an individual. It maintains good health and prevents or cures diseases as well. 4
Avicenna detailed the mechanism of actions, varieties, methods, special exercise for each organ, therapeutic exercise, the limit and amount of Riyazat. 4

Greek physicians in the BC century have paved great attention to this important task in a ratiocinative way. They elaborated on the concept of health and factors which are essential for its maintenance. Among them, Riyazat (exercise) is a very basic and useful tool for the maintenance of health. As well as, other recommendations of exercise have also described by Greek physicians. Unani physicians provided cognitions regarding timing, modes, and benefits of Riyazat. 5

Ibn Sina has said that a person who is doing regular exercise at a given time he will save from all temperamental and humoral disturbances which occur in the body.6,7 Allama Moh. Kabeeruddin said that exercise is an irreplaceable regimen. 


\section{Lifestyle diseases:}

Lifestyle diseases are ailments that are primarily based on the day to day habits of people. Habits that detract people from the activity and push them towards a sedentary routine can cause several health issues that can lead to chronic noncommunicable diseases that can have near life-threatening consequences. ${ }^{9}$

Chronic diseases, frequently classified as a major component of non-communicable diseases (NCDs), usually affects the middle or old age individuals after prolong exposure

to an unhealthy lifestyle relating mainly to economic

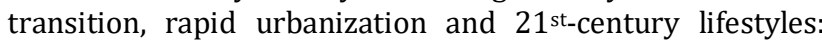
tobacco use, harmful consumption of alcohol, unhealthy fast food diet, insufficient physical activity and extended office working hours. NCDs are by far the leading cause of death worldwide. In 2016, they were responsible for $71 \%$ (41 million) of the 57 million deaths, which occurred globally. The major NCDs responsible for these deaths included cardiovascular diseases (17.9 million deaths, accounting for $44 \%$ of all NCD deaths and $31 \%$ of all global deaths); cancers ( 9 million deaths, $22 \%$ of all NCD deaths and $16 \%$ of all global deaths); chronic respiratory diseases (3.8 million deaths, $9 \%$ of all NCD deaths and 7\% of all global deaths); and diabetes (1.6 million deaths, $4 \%$ of all NCD deaths and $3 \%$ of all global deaths). The global probability of dying from one of the four main NCDs in 2016 was $18 \%$, with a slightly higher risk for males (22\%) than for females (15\%). Nowadays, lifestyle disorders are becoming more common, affecting the younger population especially the young, urban population. ${ }^{10}$

Non-communicable diseases (NCDs) kill around 40 million people each year, which is around $70 \%$ of all deaths globally ${ }^{8}$. NCDs are chronic in nature and cannot be communicated from one person to another. They are a result of a combination of factors including genetics, physiology, environment and behaviors. The main types of NCDs are cardiovascular and chronic respiratory diseases in addition to cancer. NCDs such as cardiovascular diseases (CVD), stroke, diabetes and certain forms of cancer are heavily linked to lifestyle choices, and hence, are often known as lifestyle diseases. ${ }^{9}$

A lifestyle with lack of physical activity often referred to an as sedentary lifestyle, is one of the leading causes of preventable mortality worldwide. ${ }^{12}$

The causes of NCDs can be divided into three broad categories: modifiable behavioral risk factors, nonmodifiable risk factors and metabolic risk factors.

Modifiable behavioral risk factors: Behavioral risk factors such as excessive use of alcohol, bad food habits, eating and smoking tobacco, physical inactivity, wrong body posture and disturbed biological clock increase the likelihood of NCDs. ${ }^{11}$

A simple lack of physical activity has been claiming 1.6 million lives annually. 10

The common emerging sedentary lifestyle disorder includes obesity, hypertension, diabetes and cardiovascular diseases which are the consequences of lack of physical activity and exercise. ${ }^{9,12}$

The rising prevalence of anxiety and depression is also the result of the same.

\section{Benefits of Riyazat}

It improves Istehala (metabolism) for the proper functioning of the body, controls weight, improves mood and boosts energy.

It helps in the removal of waste products through natural routes.

\section{It tones up Individual organs.}

It maintains and improves flexibility, coordination and balance of the musculoskeletal system and thus strength in the body as a whole.

It relieves depression and anxiety, insomnia.

During exercise, pores of the body become open.

It fortifies the ligament, cartilage, nerves and joints.

Exercise strengthens the Quwate Dafia (faculty of evacuation) and Quwate Hazma (digestive faculty) ${ }^{13}$

\section{Exercise recommendations for health:}

The ACSM recommends that people of all ages accumulate 30 minutes of moderate physical activity on most, if not all, days of the week. Brisk walking is an example of the type of activity recommended and can easily be incorporated into most people's lives. Adherence to a regular program is essential as the health benefits are quickly lost on cessation of activity. ${ }^{14}$

\section{Biological mechanisms of exercise in health:}

Physical fitness, achieved through regular exercise and spontaneous physical activity, confers resilience by inducing positive psychological and physiological benefits, blunting stress reactivity, protecting against potentially adverse behavioral and metabolic consequences of stressful events and preventing many chronic diseases. Physical fitness appears to buffer against stress-related diseases owing to its blunting/optimizing effects on hormonal stress-responsive systems, such as the hypothalamic-pituitary-adrenal axis and the sympathetic nervous system. Another mechanism whereby regular exercise may confer resilience is through minimizing excessive inflammation. Chronic psychological stress, physical inactivity and abdominal adiposity have been associated with persistent, systemic, low-grade inflammation and exert adverse effects on mental and physical health. It is now thought that inactivity leads to toxic levels of unused oxygen and a high energy state in a mitochondrion. This creates more free radicals that cause damage to the mitochondrion and, therefore, the cell. Damaged mitochondrion creates inflammation, faster aging and leads to most long term conditions. Exercise, therefore, increases the resilience of every cell and this is done by anti-oxidants and these are stimulated by physical activity. Thus exercise has such far-reaching benefits to health. ${ }^{15,16}$

\section{Exercise in obesity:}

Stable body weight is maintained by balancing energy intake, by food consumption, with energy expenditure. While metabolic systems can adjust for short term changes in equilibrium, a long term imbalance of energy intake over expenditure results in weight gain and obesity. Successful weight loss is achieved by reducing caloric intake and increasing energy expenditure.

Daily physical activity which accounts for approximately 20$30 \%$ of total energy expenditure is the best way of modifying total energy expenditure. Most studies base their design on the recommended physical activity guidelines for health, 30 minutes of exercise on 5-7 days per week. A brisk walking 
speed will expend approximately $7 \mathrm{kcal} / \mathrm{min}$. over 30 minutes that accumulates to approximately $210 \mathrm{kcal}$. There is $9000 \mathrm{kcal}$ in $1 \mathrm{~kg}$ of body fat. Therefore it would take approximately 8.5 weeks to lose $1 \mathrm{~kg}$ of body weight if exercising five times per week. ${ }^{14}$ Eating patterns and maximizing physical activity are advised concerning modest extra activity required to increase physical activity level (PAL) ratios. When possible, walking rather than driving to work should be incorporated in daily routine, since this is more likely to be sustained. Swimming may be advised if necessary. 17

Hippocrates, the most famous herodicus student, wrote on the beneficial effects of the exercise and its value in decreasing obesity. 4

The Unani physician-prescribed exercise as it removes laziness and heaviness of body and it makes the body active and light in weight. ${ }^{18,19}$

They said that exercise opens the pore of the body and then there is the removal of waste products from the body. ${ }^{18}$ When pores open there is increased sweating and hence it helps lose weight. So they were aware of the benefits of exercise in obesity.

\section{Exercise in Diabetes:}

Most patients with type 2 diabetes are overweight or obese, with a high waist to hip ratio, while most obese patients are insulin resistant, though not as severe as those with type 2 diabetes. Both groups usually have altered lipid metabolism with high triglycerides, LDL, total cholesterol and low HDL cholesterol and an increased risk of cardiovascular diseases. ${ }^{14}$

Exercise has multiple positive benefits, including cardiovascular risk reduction, reduced blood pressure, maintenance of muscle mass, reduction in body fat and weight loss. For individuals with type 1 or type $2 \mathrm{DM}$, exercise is also useful for lowering plasma glucose and increasing insulin sensitivity. 20

In patients with diabetes, the ADA recommends 150 $\mathrm{min} /$ week (distributed over at least three days) of moderate aerobic physical activity with no gaps longer than two days. ${ }^{20}$

The chosen aerobic exercise should use large muscle groups. Running, walking, biking and swimming are excellent activities for most people. ${ }^{20}$ Unani physicians recommended these exercises with the name of Ahzaar (running), Musaabqat (brisk walking) and riding in the form of horse riding, camel riding. ${ }^{13,18}$ The exercise regimen should also include resistance training which was described by Unani physicians with the name of Mubaatshat.18,20

People who do regular exercise, low level of insulin is sufficient to control their blood glucose level as exercise decreases the requirement of insulin in people. ${ }^{13}$

Food intake and insulin doses should be adjusted based on the intensity and duration of anticipated exercise because these patients are prone to either hyperglycemia or hypoglycemia. ${ }^{20}$

Unani physicians recommended exercise as it strengthens nerves so that it may prevent neuropathic diseases related to diabetes. ${ }^{19}$

\section{Exercise in cardiovascular diseases:}

The fact that the risk of cardiovascular disease is significantly greater in obese and type 2 diabetes patients has been well established. In addition to metabolic changes relating to weight loss and insulin resistance, exercise also confers many benefits to the cardiovascular system.

Blood volume changes: The first detectable effect of sustained exercise is an increase in circulating blood volume of around $10-20 \%$ (500-1000 ml), which can be seen almost to its full extent after even a two-hour aerobic training bout and is sustained throughout a period of regular training.

Blood pressure control: Regular exercise leads to a reduction in blood pressure by improving arterial dilatation. This response occurs after only a few weeks of exercise. Exercise, therefore, is increasingly favored as a therapeutic aid for patients with hypertension.

Structural and functional adaptations of vasculature: With regular exercise, structural and functional changes in the vasculature are observed, which enhances oxygen delivery and uptake during exercise. It induces cellular reorganization and endothelial mediated alterations in gene expression of several substances. Additional structural adaptations include angiogenesis and arterial and venous remodeling.

Regular exercise increases oxygen delivery, uptake and utilization in the muscle cells. Cardiac muscle responds to exercise similarly to skeletal muscles. It increases the force of muscular contraction and therefore, the volume of blood ejected by each beat. By improving arterial dilatation and blood pressure, it reduces the stress placed on the heart and reducing the risk of myocardial disease. 14

Unani physicians recommended exercise in cardiovascular diseases like khafqaan barid and rutoobat-e-qalb/ikhtilaj-eqalb as it provides taskheen to the heart.21

\section{Exercise in stress and anxiety disorders:}

Exercise is also considered vital for maintaining mental fitness, and it can reduce stress. Studies show that it is very effective at reducing fatigue, improving alertness and concentration, and enhancing overall cognitive function.

Exercise and other physical activity produce endorphins chemical in the brain that acts as natural painkillers and also improve the ability to sleep, which in turn reduces stress.

Scientists have found that regular participation in aerobic exercise has been shown to decrease overall levels of tension, elevate and stabilize mood, improve sleep and selfesteem.

About 5 minutes of aerobic exercise can begin to stimulate anti-anxiety effects.

Stress and anxiety are normal parts of life, but anxiety disorders which affect 40 million adults are the most common psychiatric illness. Psychologists studying how exercise relieves anxiety and depression suggest that a 10 minutes walk may be just as good as a 45 -minute workout. A brisk walk or other simple activity can deliver several hours of relief, similar to taking aspirin for a headache.

Science has also provided some evidence that physically active people have lower rates of anxiety and depression than sedentary people. Exercise may improve mental health by helping the brain cope better with stress. ${ }^{22}$

Hippocrates wrote about the effects of exercise in improving mental attitude. ${ }^{4}$

\section{Conclusion:}

Despite knowing about the beneficial effects of exercise in the prevention and control of lifestyle diseases, it would appear that this knowledge has not influenced the behavior 
of the vast majority of the population. The prevalence of people who have a sedentary lifestyle is increasing day by day and the accompanying health consequences of this are of considerable concern. There is, therefore, an onus on health professionals to utilize every opportunity to prescribe exercise when involved with individuals having these diseases or with risk factors for these conditions.

\section{References:}

1. Rushd Ibn M. Kitab-ul-Kulliyat. New Delhi: CCRUM, 1980; 344-346

2. Majoosi AIA. Kamilus Sana'ah, Idara kitab-us-shifa, Vol-I. New Delhi: CCRUM, 2010; 228

3. Kisner C, Colby LA. Therapeutic exercise. 1st ed. New Delhi: Jaypee Brothers Medical

Publishers; 2003.

4. Sameena Firdaus et al. Riyazat (exercise): a part of ilaj bil tadbeer and its role in prevention of diseases. IJDR, 2016; 6(1), 64866498

5. Aslam $\mathrm{M}$ et al. Riyazat (exercise) in The Perspective of Unani System of Medicine and its Importance in Life - A Review. American Journal of PharmTech Research 2015; 5 (3)

6.Ibn Sina, Al Qanoon Fi't Tibb, Urdu translation by Kantoori Hasnain Ghulam, Idara Kitab-us-Shifa New Delhi. Vol. 1, YNM; 174

7. Gruner, Oskar Cameron. A treatise on the Canon of Medicine of Avicenna. Vol. 1, AMS press New York. 1973; 384

8.WHO (2017). Non-communicable diseases. http://www.who.int/mediacentre/factsheets/fs355/en/ on: 2/05/2017), lifestyle diseases

9. Tabish A S et al. Lifestyle Diseases: Consequences, Characteristics, Causes and Control. Journal of cardiology and current research, 2017; 9 (3), 326

10.WHO,Non-communicable diseases country profiles 2018 https://www.who.int/nmh/publications/ncd-profiles-2018
11. Sharma M, Majumdar PK. Occupational lifestyle diseases: An emerging issue. Indian Journal of Occupational and Environmental Medicine, 2009; 13(3), 109-112

12. Senapati Sabyasachi et al. Modern Lifestyle Diseases: Chronic Diseases, Awareness and Prevention. IJCRA, 2015; 3 (7), 215223

13. Ehsanullah M., Ilaj-bil-Tadbeer, Rabbani printers Delhi. 2006; 70, $72-73$

14. Gormley John, Hussey Juliette, Exercise therapy prevention and treatment of disease, Blackwell Publishing Ltd. 2005; 4-5, 22, $65-67,69,125,130$

15. Silverman MN, Deuster PA. Biological mechanisms underlying the role of physical fitness in health and resilience. https://www.ncbi.nlm.nih.gov/pubmed/25285199

16. P. Darrell Neufer et al. Understanding the Cellular and Molecular Mechanisms of Physical Activity-Induced Health Benefits. https://www.sciencedirect.com/science/article/pii/S15504131 15002235

17. Nicki R. Colledge, Walker R. Brian, Ralston H. Stuart, Davidson 's Principles \& Practice of Medicine, Churchill Livingstone Elsevier, $21^{\text {st }}$ edition. 2010; 118-119

18. Kabeeruddin Moh. Hakim, Kulliyat-e-Qanoon, Idara kitab-ulshifa. 2015; 137-139, 141-145

19. Kabeeruddin Moh. Allama, Kulliyat-e-Nafeesi, Idara kitab-ulshifa. YNM; 417-418, 421-422

20. Jameson, Fauci, Kasper, Hauser, Longo, Loscalzo, Harrison's Principles of Internal Medicine, Mc graw hill education, $20^{\text {th }}$ edition. 2018; 2409

21.Khan Azam Mohd. Hakim, Ikseer-e-Azam, Idara kitab-ul-shifa. $2011 ; 171-172,177,251,357,373$

22. Anxiety and Depression Association of America, Managing Stress and Anxiety, https://adaa.org/living-with-anxiety/managinganxiety. 